deeply considered study of Brazilian finance is important for both historical and current studies of financial fragility. Taking up the questions that the book raises can also make important contributions to understanding long-term growth and inequality in locations where "development" did not happen or was delayed.

GAIL D. TRINER, Rutgers University

\title{
GENERAL AND MISCELLANEOUS
}

Education Matters. Global Schooling Gains from the $19^{\text {th }}$ to the $21^{\text {st }}$ Century. By Robert J. Barro and Jong-Wha Lee. New York: Oxford University Press, 2015. Pp. xi, 289. $\$ 34.95$, hardcover.

doi: $10.1017 / \mathrm{S} 0022050716000929$

Robert Barro and Jong-Wha Lee clearly believe that education matters if their scholarly collaboration over the past quarter-century is any indicator. Their 1993 article ("International Comparisons of Educational Attainment," The Journal of Monetary Economics 32, no .3 [1993]: 363-94) set forth the details of a data set they had compiled on adult educational attainment between 1960 and 1985 for 129 countries. This reflected their interest in cross country variation in educational attainment as a determinant of cross-country variation in rates of economic growth. Since then they have collaborated on extending the coverage of this data set both chronologically and geographically as well as making various modifications in estimation procedures in numerous publications. This data has become a standard source in cross country econometric analysis and ongoing updates are available at their website, barrolee.com. In the Preface to the book under review, the authors outline the further contributions to this effort they hope it will provide. These include providing estimates on school enrollment and educational attainment back to 1870 from a previous ending point in 1960, providing projections of educational attainment through 2040, developing a data set on the quality of education based on internationally comparable test scores, and utilizing both a 76 country panel data set spanning 1960 to 2010 and a 40 country panel data set with coverage at five year intervals between 1870 and 2010 to examine the effects of educational attainment on economic growth, fertility, and democracy.

The extent of the geographical and chronological coverage is impressive and this book is suggestive and informative in a number of respects. It provides a panorama of trends in educational attainment world-wide over the last century and a half. However, the book only reports trends by broad geographical areas; their country level estimates are available on their open access website. Their effort at projections of educational attainment over the next 30 years are quite suggestive pointing to the role of both changing age structure and recent increases in enrollment rates at various education levels on likely future trends in international educational attainment. The results in the two chapters on the effects of educational attainment are interpreted as supporting the authors' claims that education does indeed matter. One notable set of findings is that the impact of female educational attainment has a generally more positive impact on economic growth, negative impact on fertility and positive impact on prevalence of democracy compared with male educational attainment. One of these two chapters also 
provides worthwhile exercises in development and growth accounting with the plausible conclusion that given the larger change in output per person than in educational attainment human capital improvement explains a substantial but not the preponderance of increase in output per person and growth rates over the past 50 years. Their final chapter, on educational quality, synthesizes both international test score data and various measures of education quality based on a mincer equation framework utilizing labor market returns to education.

While this book contains worthwhile material, it also has important limitations.

The underlying enrollment data seem frequently taken from secondary international compendia rather than directly from national sources which raises concerns about how carefully data quality has been scrutinized. Moreover, in some instances, particularly in the historical data before 1960 and especially in coverage they give between 1820 and 1870 , there are considerable numbers of missing direct observations filled in through linear and logistic interpolation and extrapolation methods. Barro and Lee make even more reliance on interpolation and extrapolation in developing estimates of adult educational attainment. As the authors note, these estimates have been challenged by a number of other studies (see, for example, D. Cohen and M. Soto. "Growth and Human Capital: Good Data, Good Results." Journal of Economic Growth 12, no. 1 [2007]: 51-76). While the authors defend their estimates compared with others as based more fully on actual direct attainment surveys, those planning to make use of their data set will want to survey these alternative studies with care to make their own assessment of data quality.

The two chapters on the economic and political impact of educational attainment make extensive use of results from cross country regressions. They provide rather terse overviews both of the underlying theories involved linking education to economic growth, fertility, and democracy and of empirical specifications. The conclusions they draw from their analysis largely consist of reporting regression coefficient estimates focusing on significance and general orders of magnitude and suggestive possibilities for interpretation. The processes at work would seem largely micro-processes and little effort is made to reconcile these with their macro level results.

More generally, an important limitation of cross country growth regression analysis is that it cannot directly ascertain the channels of influence between explanatory variables and outcomes of interest. And while the authors refer to the ample body of research using cross country analysis to examine the impact of education, they do not relate their findings to this research in any depth.

Readers of this JouRnaL will presumably be interested in Barro and Lee's findings employing their newly developed "historical" data set extending back to 1870 with coverage through 2010 as reported in Chapter 5 on the effects of education on growth, fertility, and democracy. However, they use this extension 90 years back in time from the 1960 starting point in Chapter 4 to do no more than provide additional observation points. As already noted their discussion consists of terse summaries and interpretations of their estimated regression coefficients on assorted education variables. Questions about long run trends such as how the economic and social impact of human capital has changed over the last 140 years in light of technological developments, whether this has changed as the basic sectoral structure of the economy has changed, and on whether convergence in educational attainment across countries has influenced changes in international specialization patterns are not addressed. And their projections of educational attainment trends in Chapter 3 are based primarily on trends in age structure and 
enrollment leaving open such questions as what a supply and demand model might imply about whether there will be an ongoing race between technology and schooling.

Thus, the book ends up treating the term "matters" in its title more as noun than verb, that is as a compilation of material. While it reflects substantial effort at both measurement and analysis, Education Matters leaves much for further work on both scores.

\section{DAVID Mitch, University of Maryland}

The Idea of History in Constructing Economics. By Michael H. Turk. London: Routledge, 2015. Pp. viii, 242. $\$ 160.00$, cloth.

doi: $10.1017 / \mathrm{S} 0022050716001108$

Contrary to the impressions of many, the history of economic thought differs from economic history. The history of thought is a branch of intellectual history - the history of ideas. Economic history can be thought of as the history of growth and development. My current interests are in economic history, although for a decade and a half early in my career I also taught thought, so I have some acquaintance with the field. At that time, I read many of the classic (and some not so classic) works in economics and found this often enlightening in ways that influenced my research. Old ideas weren't necessarily bad, and although much in our discipline's past has been appropriately discarded (e.g., the labor theory of value), and much incorporated in modern thinking, it is also true that concepts or ways of approaching problems have sometimes been prematurely discarded. I learned that a careful and critical reading of texts in economics with an eye to resurrecting approaches that have not outlived their usefulness could be useful, supporting the view that the study of thought (which often meant the history of economic theory) can be a valuable complement to historical and empirical research in economics.

When asked to review this book, I therefore approached it with some enthusiasm. I was not familiar with the author, but we sometimes learn a great deal when serendipity or happenstance moves us outside of our usual circle. But I also approached the review with a caution bred from experience. Although reading original texts in economics had proved rewarding, reading books or articles about texts in economics (history of economic thought) often had not.

Turk's book is entitled The Idea of History in Constructing Economics. It is actually more about the ideas of physics, mathematics, philosophy, and to a lesser extent, biology and economic history in constructing economics. It consists of ten chapters, five based on previously published articles. It includes, inter alia, detailed discussions of Leon Walras and general equilibrium theory, Joan Robinson and the arrow of time, Max Weber, and also the relationship between economics and economic history, with particular focus on the ideas of Brian Arthur, Paul David, and Paul Krugman. One finds as well chapters on puzzle solving vs. problem solving in economics, and on the nature and meaning of historical proof.

I wish I could say that I felt enlightened and invigorated after completing this book. The author has read a great deal and is clearly familiar with a wide range of literatures in economics, science (particularly physics and mathematics), the philosophy of science, and economic history. The book has its share of esoteric epistemological terms (you had best know what nomothetic and idiographic mean), but for this style of work the jargon is not excessive. 